\title{
Impact of Age on Skills Development in Different Groups of Students
}

\author{
Mahipatsinh D. Chavda and Bharat S. Trivedi
}

\begin{abstract}
The purpose of the present research is to study the development of different skills belonging to different age groups of students. Life skills are the key to success. There are variations in the life skills in different individuals. It is assumed that the life skills develop gradually. The main components of life skills are communication, inter-personal skills, decision making, critical thinking, coping and self management skills. They develop as the individual matures, according to age. With the passage of time, the different component of life skills grows. The Prime objective of present study was to evaluate the development of life skills in different age groups. The sample of 150 students ( 75 boys and 75 girls) belonging to different age groups were selected randomly from schools and colleges of Ahmedabad of Gujarat (India). Life skills test was administered to measure the types of life skills; 1) Social etiquettes 2) Communication 3) Self esteem and 4) Hygiene. The result shows that there is significant difference in skills development, when age of students is increases from 11 to 20 years. There is no significant difference found in boys and girls from age of 11 to 20 years. In certain age group of girls, skills development is found better than boys.
\end{abstract}

Index Terms-Communication, development, hygiene, life skills, self esteem, social etiquettes.

\section{INTRODUCTION}

Life skills are the key to success. Life skills are problem solving behaviors used appropriately and responsibly in the management of personal affairs. They are a set of human skills acquired via teaching or direct experience that are used to handle problems and questions commonly encountered in daily human life. There are variations in the skills of different individuals and that is why we found differences in the success and achievements of individuals.

UNICEF states "there is no definitive list" of life skills but enumerates many "psychosocial and interpersonal skills generally considered important." It asserts life skills are a synthesis: "many skills are used simultaneously in practice. For example, decision-making often involves critical thinking ("what are my options?") and values clarification ("what is important to me?"), (How do I feel about this?"). Ultimately, the interplay between the skills is what produces powerful behavioural outcomes, especially where this approach is supported by other strategies..."[1].

UNICEF has mentioned certain life skills. According to it,

Manuscript received November 7, 2013; revised January 22, 2014.

Mahipatsinh D. Chavda is with Department of Psychology, L. D. Arts College, Gujarat University, Ahmedabad, Gujarat, CO 380009 India (e-mail: chavda.m.d@gmail.com).

Bharat S. Trivedi is with Arts, Commerce \& Science College, Lunawada, Gujarat University, CO 389230 Gujarat, India (e-mail: trivedibharat80@gmail.com). the main components of life skills are communications, interpersonal skills, decision making, critical thinking and self management. Inter personal communications contain verbal and non-verbal communications, active listening, expressing feelings, giving and receiving feedback. Negotiation and refusal skills are also a part of life skills, which is related within interpersonal communication. Decision making and critical thinking skills contain the following things; a) Information gathering skill b) Evaluating consequences of present action for self and others c) Determining alternative solution of problems and d) Analyzing skills regarding the influence of values and attitudes of self and others. Coping, is expending conscious effort to solve personal and interpersonal problems, and seeking to master, minimize or tolerate stress or conflict [2]. Various life skills develop as the individual matures with the increase of age e.g., the inter communication skill develops as the individual matures.

In the present study, the aim is to discover the dimensions of various life skills. The perception is that life skills evolve and develop with age. The aim of the present study is to understand the impact of age on the development of skills in students of different age groups.

\section{REVIEW OF Literature}

Many researchers have worked on the impact of different parameters on life skills. In an ideal world, the objective of education in life skills would be to educate everyone in those skills required in order to face every mission in each stage of their life. This education emphasises more developmentally than correctional (Nelson - Jones R 1998, Megel M et al., 1994) [3].

\section{A. Life Skill Projects}

While making claims for the success or failure of a life skill program it is important to note that the program affects the behavior of children. Children will be strongly influenced by the ideas, values, and practice around them at home and in their community. A life skill program is that which considers these and involves key people in the children's life. The following effects are found in children.

- Many children live in a many circumstances that make them especially vulnerable and limits their choices and future potential.

- Life skill learning does not change events but helps children to cope better with these events enrich the world they live in.

- Life skills learning should help children become aware of

1) What they are doing?

2) How they obtain information. 
3) How they think, feel and behave with better understanding about themselves and others, they can make better choices [4].

\section{B. Evaluation of Life Skills in Students of Nursing: A Descriptive Study}

The study was conducted by Dimitrios E. Papageorgiou, Anna Kavga, RN. The aim of the study was the determination of nursing students' opinions with regard to the existence of life skills and to what degree they impact. The answers of 144 students of two Nursing departments in Greece were evaluated using a questionnaire in order to determine their opinions about the non-existence or existence of life skills and if so what level of impact they had on. The questionnaire included 69 questions describing the following seven dimensions of life skills: emotion, thought, relations, study, professional settlement, leisure time, mental - bodily health. The answers were given based on the 4 point Likert scale. The descriptive analysis of this questionnaire showed that the sample of students had an effectual or a large need of improvement at a percentage of $42.9 \%$ in the emotional sector, $32.2 \%$ in the sector of thought, $31 \%$ in the sector of relations, $41.3 \%$ in the sector of study, $32.7 \%$ in the sector of professional settlement, $30.7 \%$ in the sector of leisure time and $35.1 \%$ in the sector of health. Mann -Whitney U control showed statistically important differences in 23 of the 69 questions. The Pearson's cross-correlation parametric coefficient showed that they should emphasize in sectors as maintenance of balance between work, personal relations and family, as well as decision-making. The objective of education in life skill is to help people increasing the probability of making good and no insufficient choices in targeted skills [5].

\section{Psychological Life Skills and Mental Health}

The study was conducted by M.Noor Rochman Hadjam (University of Gadjah Mada) and Wahu Widhiarso (UGM). The aim of this study was to test conceptual model that showed the role of life skills to mental health. The participants of the study were teachers $(N=200)$ from various provinces in Indonesia. Life skills were measured by life skill scale that consists of six life skill dimensions, while mental health was tested by measurement model of structural equation model (SEM). Those measurement model, each variable was tested by ( $x 2=11-54 P>.05)$. Analysis using SEM showed that model has goodness fit indices ( $x 2$ $=562-13 P>0.05)$. The score of life skills that in concludes score dimensions emotional skill, social skill; self-esteem; thinking and problem solving are able to predict individual's mental health. The results produced strong support to the activation of mental health improvement of individuals through life skill programs [6].

\section{Emotion Communication Skills in Young, Middle-Aged, and Older Women}

In 1987 Malatesta, Carol Z.; Izard, Carol E.; Culver, Clayton; and Nicolich, Mark assessed the effectiveness of an emotion induction procedure for the study of emotional communication in adults; we also gathered preliminary age-comparative data on the expressive and receptive capacities of a sample of adult women. Young, middle-aged, and older women (encoders) related emotional experiences following mood induction and then assessed the intensity of their affective experiences. Videotapes of these sessions (facial expressions only) were shown to young, middle-aged, and older female judges (decoders), who rated the encoders for emotional intensity as well as for the type of effect being communicated. Validity and reliability issues with respect to the procedure's usefulness are discussed. Decoding accuracy was found to vary with age congruence between encoder and decoder, suggesting a decoding advantage accruing through social contact with like-aged peers. Older decoders did most poorly, but a differential warm-up effect was evident, suggesting that the performance of older subjects might be enhanced with practice. There were also trends suggesting that the affective expressions of older subjects may be harder to decode owing to age-related structural changes in the face [7].

\section{OBJECTIVES}

1) To study the impact of age on skills development in different groups of students

2) To study the effect of gender on the development of skills

3) To make aware the students about their skills

4) To aware the students about the key role of life skills in personality development

\section{HYPOTHESIS}

1) There is no significant difference between ' $A$ ' and ' $B$ ' group of students.

2) There is no significant difference between ' $B$ ' and ' $C$ ' group of students.

3) There is no significant difference between ' $A$ ' and ' $C$ ' group of students.

4) There is no significant difference in group $A^{1}, B^{1}, C^{1}$ and $\mathrm{A}^{2}, \mathrm{~B}^{2}, \mathrm{C}^{2}$.

5) There is no significant difference between $A^{1}$ and $A^{2}$ group of students.

6) There is no significant difference between $\mathrm{B}^{1}$ and $\mathrm{B}^{2}$ group of students.

7) There is no significant difference between $C^{1}$ and $C^{2}$ group of students.

8) These are the major hypothesis of the present study.

\section{VARIABLES}

TABLE I: LIST OF VARIABLES

\begin{tabular}{ccc}
\hline \hline Name of Variable & Nature of Variable & Number of Variable \\
\hline Age Groups & IV & 03 \\
Gender & IV & 02 \\
Skills & DV & 04 \\
IV = Independent Variable & & \\
DV = Dependent Variable & &
\end{tabular}

Following variables, as mentioned in Table I were taken for present study. 


\section{SAMPLING}

TABLE II: AGE AND GENDERWISE CLASSIFICATION OF STUDENTS

\begin{tabular}{cccc}
\hline \hline Group & Boys & Girls & Total \\
\hline A (11 to 13 years) & 25 & 25 & $\mathbf{5 0}$ \\
B (14 to 17 years) & 25 & 25 & $\mathbf{5 0}$ \\
C (18 to 20 years) & 25 & 25 & $\mathbf{5 0}$ \\
\hline Total & 75 & 75 & 150 \\
\hline \hline
\end{tabular}

\section{Methodology}

In the present study, Walker's Life Skills Test (2009) [8] was used. The test is taken from internet. This test measures four types of life skills 1) Social etiquettes 2) Communication (3) Self esteem and (4) Hygiene.

150 students were selected randomly from schools and colleges of Ahmedabad city. Age wise students were divided in three groups namely A, B, and C (Table II). Group 'A' consisting of students having age of 11 to 13 years, in group ' $\mathrm{B}$ ' age of 14 to 17 years and in group ' $\mathrm{C}$ ' age of 18 to 20 years. Group A1, B1 and C1 is for boys and group A2, B2 and $\mathrm{C} 2$ is for girls. Each group is of 50 students ( 25 boys and 25 girls in each group). ' $t$ ' test was used to analyze the data statistically.

\section{RESUlt AND DISCUSSION}

TABLE III: SKILLS DEVELOPMENT IN AGE OF 11-13 YeARS AND 14-17

\begin{tabular}{ccccccc}
\multicolumn{7}{c}{ YEARS $(N=100)$} \\
\hline \hline Group & $N$ & Mean & SD & SEM & $t$ & Level \\
\hline A & 50 & 13.22 & 2.30 & 0.32 & & SG \\
B & 50 & 15.72 & 3.06 & 0.43 & 4.6224 & 0.01 \\
\hline \hline
\end{tabular}

The ' $t$ ' value is 4.62 which is significant at 0.01 level (see in Table III). It means there is significant difference between students of 11-13 years and 14-17 years. It shows that the students of age of 14-17 years were more competent than students of age of 11-13 years towards development of life skills. This results are also coincides with previous work carried out by other researcher. Thus hypothesis 1 is rejected.

TABLE IV: SKILlS DEVELOPMENT IN AGE OF 14-17 YEARS AND 18-20

\begin{tabular}{ccccccc}
\multicolumn{7}{c}{ YEARS $(N=100)$} \\
\hline \hline Group & $N$ & Mean & SD & SEM & $T$ & Level \\
\hline B & 50 & 15.72 & 3.06 & 0.43 & & SG \\
C & 50 & 17.70 & 2.89 & 0.41 & 3.3254 & 0.01 \\
\hline \hline
\end{tabular}

TABLE V: SKILLS DEVELOPMENT IN AGE OF 11-13 YEARS AND 18-20

\begin{tabular}{ccccccc}
\multicolumn{7}{c}{ YEARS $(\mathrm{N}=100)$} \\
\hline \hline Group & $N$ & Mean & SD & SEM & $T$ & Level \\
\hline A & 50 & 13.22 & 2.30 & 0.32 & & SG \\
C & 50 & 17.70 & 2.89 & 0.41 & 8.5728 & 0.01 \\
\hline \hline
\end{tabular}

The calculated ' $t$ ' value is 3.32 , which is significant at 0.01 level. Table IV shows that the mean value of group B is less than group C. It shows that the students of the age of 18-20 years found more effective than the students of 14-17 years on skills development. Hence second hypothesis is rejected.

The ' $t$ ' value is 8.57 , it is significant at 0.01 level. Table $\mathrm{V}$ shows the mean score of 11-13 years, which indicates that skills development of students of 11-13 years, is less than students of 18-20 years. It indicates that the students of 18-20 years have more skills development than the students of 11-13 years. It illustrates the effect of age on life skills development. Thus third hypothesis is rejected.

\begin{tabular}{ccccccc}
\multicolumn{6}{c}{ TABLE VI: SKILlS DEVELOPMENT IN AGE OF 11-20 YeARS $(N=150)$} \\
\hline \hline Group & $N$ & Mean & SD & SEM & $T$ & Level \\
\hline $\mathrm{A}_{1} \mathrm{~B}_{1} \mathrm{C}_{1}$ & 75 & 15.11 & 2.70 & 0.31 & & \multirow{2}{*}{ NS } \\
$\mathrm{A}_{2} \mathrm{~B}_{2} \mathrm{C}_{2}$ & 75 & 15.99 & 3.79 & 0.44 & 1.63 & \\
\hline \hline
\end{tabular}

Table VI reveals that there is no significant difference between boys and girls in the age of 11-20 years on skills development. Hence fouth hypothesis is accepted.

TABLE VII: SKILLS DEVELOPMENT IN BOYS AND GIRLS OF 11-13 YEARS

\begin{tabular}{ccccccc}
\multicolumn{7}{c}{$(N=50)$} \\
\hline \hline Group & $N$ & Mean & SD & SEM & $T$ & Level \\
\hline $\mathrm{A}_{1}$ & 25 & 13.56 & 2.18 & 0.44 & & \multirow{2}{*}{ NS } \\
$\mathrm{A}_{2}$ & 25 & 12.88 & 2.40 & 0.48 & 1.0476 & \\
\hline \hline
\end{tabular}

The result shows that there is no significant difference found between boys and girls in the age of 11-13 years. It depicts that there is no effect of gender on the development of life skills. Thus fifth hypothesis is accepted.

TABLE VIII: SKILLS DEVELOPMENT IN BOYS AND GIRLS OF 14-17 YEARS

\begin{tabular}{ccccccc}
\multicolumn{7}{c}{$(N=50)$} \\
\hline \hline Group & $N$ & Mean & SD & SEM & $T$ & Level \\
\hline $\mathrm{B}_{1}$ & 25 & 14.40 & 2.29 & 0.46 & & \\
$\mathrm{~B}_{2}$ & 25 & 17.04 & 3.19 & 0.64 & & SG 0.01 \\
\hline \hline
\end{tabular}

The ' $t$ ' value is 3.35 , it is significant at 0.01 level. The significant difference is found between boys and girls in the age of 14-17 years. Table VIII shows that, the mean score of group B2 is higher than group B1. It means girls of this age group found better than boys on skills development. Hence sixth hypothesis is rejected.

TABLE IX: SKILLS DEVELOPMENT IN BOYS AND GIRLS OF 18-20 YEARS

\begin{tabular}{ccccccc}
\multicolumn{7}{c}{$(N=50)$} \\
\hline \hline Group & $N$ & Mean & SD & SEM & $T$ & Level \\
\hline $\mathrm{C}_{1}$ & 25 & 17.36 & 2.06 & 0.41 & & \multirow{2}{*}{ NS } \\
$\mathrm{C}_{2}$ & 25 & 18.04 & 3.55 & 0.71 & & \\
\hline \hline
\end{tabular}

The result (Table IX) shows that there is no significant difference found between boys and girls in the age of 18-20 years on skills development. There is no effect of gender found on development of skills, above the age of 18 years. Thus, seventh hypothesis is accepted.

There is no significant difference found between boys of 11-13 years and 14-17 years on skills development as ' $t$ ' value is 1.33. Again mean score of both of this group is 13.56 and 14.40 with standard deviation 2.18 and 2.29 respectively.

Result of skills development test for boys of 11-13 years and $18-20$ years provides ' $t$ ' value 6.33 , which is significant at 0.01 level. It shows that there is significant difference 
found between boys of 11-13 years and 18-20 years on skills development. Mean score for boys of 11-13 years is 13.56 and for boys of 18-20 years are 17.36. It illustrates that boys of 18-20 years have more skills development than boys of 11-13 years.

The calculated ' $t$ ' value for boys of 14-17 years and 18-20 years is 4.80 , which is significant at 0.01 level. It indicates that there is significant difference between boys of 14-17 years and 18-20 years on skills development. Mean score for both groups of boys is 14.40 and 17.36 respectively, Which indicates that the boys of 18-20 years have more skills development than boys of 14-17 years.

The ' $t$ ' value for girls of 11-13 years and 14-17 years is 5.20 , it is significant at 0.01 level. It reveals that there is significant difference between girls of 11-13 years and 14-17 years on skills development. Mean score for both groups of girls is 12.88 and 17.04. It states that, girls of 14-17 years have more skills development than girls of 11-13 years.

The ' $t$ ' value for girls of 11-13 years and 18-20 years is 6.01 which is significant at 0.01 level, it means there is significant difference between girls of 11-13 years and 18-20 years on skills development. Mean score for both groups of girls is 12.88 and 18.04. It indicates more skills development found in girls of 18-20 years than girls of 11-13 years.

The result shows that there is no significant difference found between girls of 14-17 years and 18-20 years, as ' $t$ ' value is 1.04 and mean score for both the groups of girls is 17.04 and 18.04, and the standard deviation for these groups is 3.19 and 3.55 respectively. It depicts that there is no effect of age on skills development in girls from age of 14 to 20 years.

\section{CHARTS}

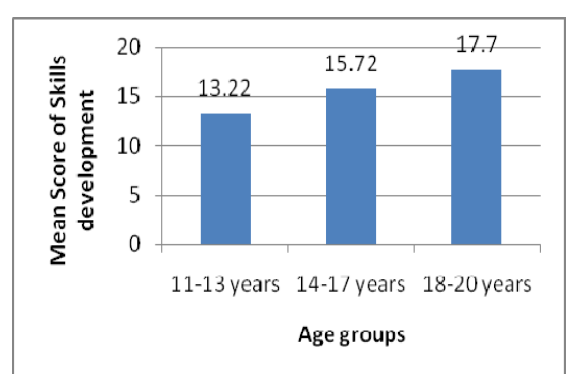

Fig. 1. Mean score of skills development of age groups 11-13 years, 14-17 years and 18-20 years.

Fig. 1 illustrates that mean score of skills development increases with increase in age from 11 to 20 years.

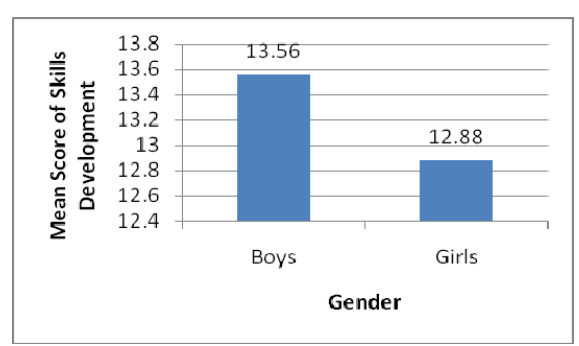

Fig. 2. Mean score of skills development of boys and girls of 11-13 years.

Fig. 2 shows that in the age of 11-13 years, boys have more skills development compare to girls.

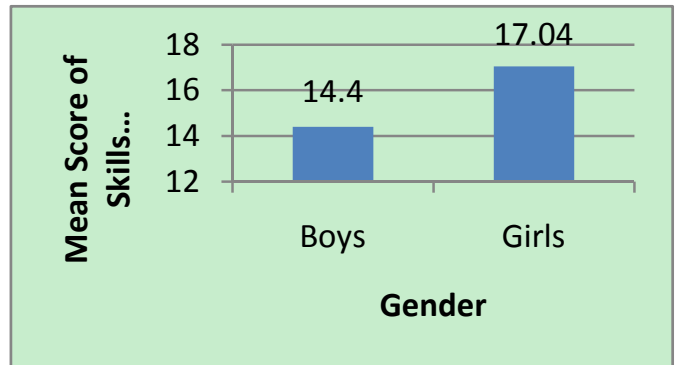

Fig. 3. Mean score of skills development of boys and girls of 14-17 years.

Fig. 3 shows that in the age of 14-17 years, girls have more skills development compare to boys.

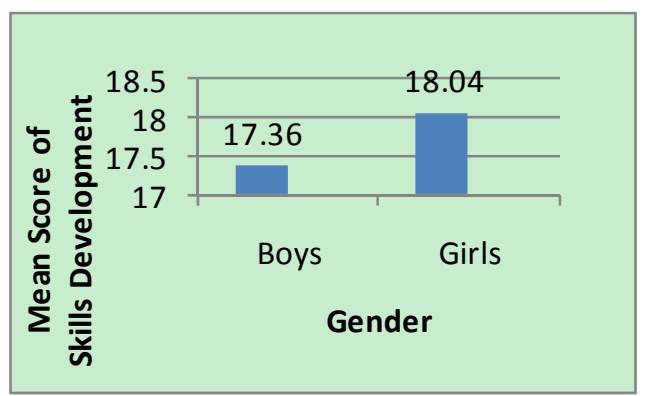

Fig. 4. Mean score of skills development of boys and girls of 18-20 years.

Fig. 4 shows that in the age of 18-20 years, girls have more skills development compare to boys.

\section{SignificANCE of RESEARCH}

Group A (11-13 Years), B (14-17 Years) and C (18-20Years) are different age groups. The result shows that B group has better Skills Development than group A and C group is better than $\mathrm{B}$. It means $\mathrm{C}$ group is better than group $\mathrm{A}$ and $\mathrm{B}$. This difference is only due to age and maturity. Age is a major affecting factor for skills development.

There is no significant difference found between Boys and Girls considering all age groups together, i.e. for all 11-20 years of age and between boys and girls of 11-13 years but we can observed that there is a difference found between boys and girls of 14-17 years and 18-20 years.

There is no significant difference found between boys of 11-13 years and 14-17 years but significant difference found in boys of 11-13 years and 18-20 years and boys of 14-17 years and 18-20 years.

There is significant difference found between girls of 11-13 years and 14-17 years and girls of 11-13 years and 18-20 years but no significant difference found between girls of 14-17 years and 18-20 years.

Several results show that girls are better than boys in skills development. This is very notable difference. In all age groups, the development of skills is better amongst girls as compared to the boys.

Thus, the main object of our research work is proved. Age and maturity are the only important factors for skills development. In modern times in every field of life women are stronger than men. There are many suggestions for conclusion of this international research work.

This kind of research work is useful for teachers and students of schools and colleges. It is also fruitful to society. 


\section{REFERENCES}

[1] Life skills. Wikipedia, the free encyclopedia. [Online]. Available: http://en.wikipedia.org/wiki/Life_skills\#cite_note-1

[2] V. Jhon. Types of life skill. ICEF. [Online]. Available: http://www.unicef.org/lifeskills/index_7308.html, 2001.

[3] M. Megel, F. Wade, and P. H. Hawkins, "Promotion, self-esteem, and weight among female college freshmen," Health Values, vol. 18, no. 4, pp. 10-19, 1994.

[4] M. Singh, "Ensuring that the learning needs of all young people and adults are met through equitable access to appropriate learning and life skills programmes," Understanding Life Skill, UNESCO, Institute for Education, Hamburg, 2013.

[5] D. E. Papageorgiou and R. N. A. Kavga, "Evaluation of life skills in students of Nursing: A descriptive study," International Journal of Caring Sciences, vol. 2, Issue 3, pp. 135-141, September-December 2009.

[6] M. N. R. Hadjam, "Psychological life skills and mental health," Gadjah Mada University, Jogjakarta, Daerah Istimewa Yogyakarta, Indonesia, 2010-2011.

[7] C. Z. Malatesta, C. E. Izard, C. Culver, and M. Nicolich, "Emotion communication skills in young, middle-aged, and older women," Psychology and Aging, vol. 2, no. 2, pp. 193-203, June, 1987.

[8] J. M. Walker, S. Ed, and T. H. Walker, "Life skills pre-test / post-test," 2009.

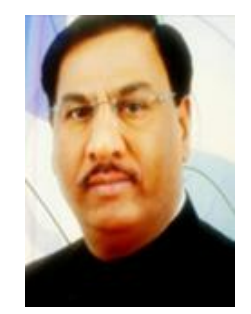

Mahipatsinh Dansinh Chavda was born on February 10th 1967 at Pachhegam, Taluka-Vallabhipur, Dstrict -Bhavnagar, State-Gujarat, India. Dr. Chavda has achieved several Academic qualifications. He received the bachelor of arts degree with psychology subject from Gujarat University, Ahmedabad, Gujarat, India in 1987. He received the master of arts degree and the M.Phil degree with psychology subject from Sardar Patel University, Vallabh Vidyanagar, District-Anand, Gujarat, India in 1989 and 1990 respectively. He also received the Doctorate degree in Psychology in the year 2003 from Saurashtra University, Rajkot, Gujarat, India.
He possesses 8 years of work experience as an assistant professor at K.H.M Arts \& Commerce College, Porbandar and 6 years as an associate professor at Arts, Commerce College, Dehgam. He was a principal at Arts College, Modasa for one year. He has been the principal of L.D.Arts college, Ahmedabad, one of the premier institutes of learning in Gujarat for 9 years. Furthermore he happens to be PROFESSOR and HEAD OF THE DEPARTMENT of Psychology at the same institute. He has an impressive record in academic research. He has published 14 research papers and 5 books thus far. He has completed 25 research projects and attended 41 Nation / International seminars / conferences / workshops and organized 6 national level seminars.

Dr. Chavda was a dean of Arts Faculty for 3 years (2011-13), Gujarat University. He has been the CHAIRMAN of Board of Studies in Psychology, Gujarat University for the past 9 years. He has been the Member of Executive Council, Gujarat University for the last 5 years and a Senate Court Member and Academic Council Member, Gujarat University for the past 9 years. He is a Life Member of Gujarat Psychology Association. Last but not the least, Dr. Chavda is a recognized Ph.D. guide in Psychology subject in Gujarat university and Dr. Babasaheb Ambedkar Open University, Ahmedabad, Gujarat, India.

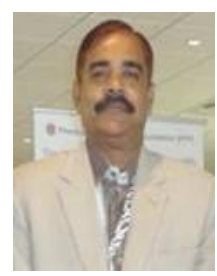

Bharat Shamaldas Trivedi was born on June 20th 1959 at Rajpipla, Taluka \& District - Rajpipla, State-Gujarat, India. He received the bachelor of arts and the master of arts degree in psychology from Gujarat University in the year 1980 and 1982 respectively. He has also received the Doctorate degree in Psychology in the year 1994 from Gujarat University, Ahmedabad, Gujarat, india.

He possesses 7 years of experience as an assistant professor at Arts \& Commerce College, Dharampur and 4 years at Arts College, Ambaji. He has been working as an associate professor at Arts College, Lunawada, Gujarat, India. Furthermore he happens to be professor and head of the Department of Psychology at the same institute. He has published 5 research papers and presented 6 research papers in National/International level conferences/Seminars.

He is a Life Member of Gujarat Psychology Association. Last but not the least, Dr. Trivedi is a recognized Ph.D. guide in Psychology subject in Gujarat university, Ahmedabad, Gujarat, India. 